\title{
Knowledge gaps in the diagnosis and management of patients with tropical diseases presenting to Canadian emergency departments: are the gaps being met?
}

Nazanin Meshkat, MD, MHSc*; Shikha Misra, MD ${ }^{\dagger}$; Cheryl Hunchak, MD, MPH ; Paula Cleiman, $\mathrm{MD}^{\ddagger}$; Yasmin Khan, MD, MPH*; Lisa M. Puchalski Ritchie, MD, PhD*

\section{ABSTRACT}

Objective: We conducted a needs assessment to identify knowledge gaps in the management of tropical diseases by Canadian emergency physicians and identify available, related continuing medical education (CME) resources.

Methods: A literature review was conducted to summarize challenges in the management of commonly encountered tropical diseases. An anonymous online survey was administered to Canadian emergency physicians using the Canadian Association of Emergency Physicians survey deployment service in July and August 2012. The survey identified self-reported gaps in knowledge and assessed knowledge using case-based vignettes. A list of CME resources was generated from a review of major academic emergency medicine journals, online cases, and conference topics from emergency medicine associations during 2010 2011. Two independent reviewers assessed the relevance of the resources; differences were resolved by consensus.

Results: From 635 citations, 47 articles were selected for full review; the majority (66\%) were retrospective chart reviews, few $(10.6 \%)$ had an emergency medicine focus, and fewer still were Canadian (8.5\%). In total, 1,128 surveys were distributed, and 296 (27\%) participants were included in the study. Most respondents reported "no" (52.4\%) or "some" (45.9\%) training in tropical medicine. Most (69.9\%) rated their comfort in managing patients with tropical diseases as "low." Few (11.1\%) respondents reported a tropical disease being misdiagnosed or mismanaged; $44.1 \%$ indicated malaria. The perceived need for further training was high (76.7\%). Conference workshops were the most highly requested CME modality, followed by case studies and podcasts. Correct answers to case vignettes ranged from 30.7 to $58.4 \%$. Although 2,038 CME titles were extracted from extensive searches, only 6 were deemed relevant.

Conclusions: Most Canadian emergency physicians have had minimal training in tropical diseases, reported a low comfort level in their management, and identified a high need for CME opportunities, which are lacking.

\section{RÉSUMÉ}

Objectif: L'étude visait à réaliser une évaluation des besoins en ce qui concerne les lacunes en matière de connaissances sur la prise en charge des maladies tropicales par les urgentologues au Canada et à relever les ressources existantes en formation médicale continue (FMC).

Méthodes: Nous avons procédé à un examen de la documentation afin de résumer les difficultés rencontrées dans la prise en charge des maladies tropicales les plus fréquentes. Un questionnaire d'enquête en ligne, anonyme a été envoyé aux urgentologues, au Canada, par l'intermédiaire du service de transmission des enquêtes de I'Association canadienne des médecins d'urgence, en juillet et en août 2012. L'enquête a permis de relever les lacunes déclarées par les intéressés en matière de connaissances et d'évaluer les connaissances à l'aide de scénarios fondés sur des cas. Une liste de ressources en FMC a été dressée à partir d'un examen des principales revues médicales spécialisées en médecine d'urgence, de cas en ligne, et de sujets de congrès organisés par des associations de médecine d'urgence en 2010 et en 2011. Deux examinateurs ont évalué, chacun de leur côté, la pertinence des ressources; les divergences d'opinion ont été résolues par consensus.

Résultats: Quarante-sept articles ont été sélectionnés en vue d'un examen complet, à partir de 635 citations. La majorité (66\%) de ces articles consistait en un examen rétrospectif de

From the *Division of Emergency Medicine, Department of Medicine, University Health Network and University of Toronto; $†$ Faculty of Medicine, University of Toronto; and $\ddagger$ Division of Emergency Medicine, Department of Family and Community Medicine, University Health Network and University of Toronto, Toronto, ON.

Correspondence to: Dr. Nazanin Meshkat, 200 Elizabeth Street, RFE-G-480, Toronto, ON M5G 2C4; nazanin.meshkat@uhn.ca.

This article has been peer reviewed. 
dossiers médicaux; un faible pourcentage (10.6\%) concernait la médecine d'urgence et un pourcentage encore plus faible se rapportait à des études canadiennes (8.5\%). Au total, 1128 questionnaires d'enquête ont été envoyés et 296 participants ( $27 \%)$ ont été retenus dans l'étude. La plupart des répondants ont fait état d'aucune formation (52.4\%) ou d'une certaine formation (45.9\%) en médecine tropicale. La majorité (69.9\%) se sentait peu à l'aise dans le traitement des maladies tropicales. Un faible pourcentage de répondants $(11.1 \%)$ a déclaré qu'une maladie tropicale avait fait l'objet d'un diagnostic erroné ou d'une prise en charge inappropriée; $44.1 \%$ ont indiqué le paludisme. II y avait une forte perception du besoin d'une formation accrue en la matière (76.7\%). Les ateliers offerts pendant les congrès a été la formule de FMC mentionnée le plus souvent, suivie des études de cas et de la baladodiffusion. Le taux de bonnes réponses dans les scénarios fondés sur des cas et présentés dans le questionnaire variait de $30.7 \%$ à $58.4 \%$. Sur 2038 titres de FMC tirés de la documentation à partir de recherches approfondies, 6 seulement ont été considérés comme pertinents.

Conclusions: La plupart des urgentologues au Canada ont fait état d'une formation minimale en maladies tropicales, d'un faible degré d'aise dans leur prise en charge, et d'un besoin important de FMC en la matière, formation qui fait défaut actuellement.

Keywords: education, emergency medicine, imported diseases, tropical diseases
Today it takes less than 36 hours to circumnavigate the world and people are on the move more than ever before. In 2001, an estimated 800 million people 'traveled': international travelers (698 million)), migrant workers (7080 million), refugees and uprooted people (22 million), undocumented migrants (1015 million), and migrant victims of human trafficking ( 0.7 million). Canada is a major immigrant-receiving and tourist destination country. ${ }^{1}$

Imported tropical illnesses, such as malaria, dengue, and typhoid, are acquired in endemic regions and diagnosed when symptoms present in nonendemic countries. ${ }^{2}$ Returning travellers, family and friends visiting from abroad, and immigrants arriving from tropical regions are at highest risk for presenting with such diseases. ${ }^{3}$ With the global rise in immigration and travel, there has been a re-emergence of tropical diseases over the past 30 years in nonendemic countries. ${ }^{2,47}$ This trend has resulted in challenges for emergency physicians, who are often the first point of contact for patients presenting with symptoms of tropical diseases.

The literature from nonendemic countries demonstrates major gaps in the diagnosis ${ }^{2,8-33}$ and management of tropical diseases. ${ }^{2,3}$ Diagnostic difficulties in identifying these diseases are often due to nonspecific symptoms and laboratory findings. ${ }^{3,9,14,19,33-37}$ Many studies have demonstrated that misdiagnosis and delays in diagnosis result from a lack of awareness of these tropical diseases among clinicians in nonendemic regions $s^{15-19,35,38}$ and the failure of the treating physician to elicit a travel history. . $^{2-4,9,11,15,17,39-41}$ Physicians often provide incorrect treatment for tropical diseases due to either misdiagnosing patients or not possessing the knowledge to prescribe evidence-based management. $3,22,35,42-47$

Given that emergency physicians are a common point of first contact into the health care system, it is imperative that they correctly identify and manage these patients as misdiagnosis and mismanagement can lead to prolonged illness or serious adverse events. We conducted a multifaceted needs assessment to identify knowledge gaps in the management of tropical diseases by Canadian emergency physicians and to identify available continuing medical education (CME) resources.

\section{METHODS}

Knowledge gaps were assessed through three methods: a literature review, an online survey administered to Canadian emergency physicians, and an identification and evaluation of currently available educational tools pertaining specifically to tropical diseases.

\section{Literature review}

A review was conducted to identify the literature examining the knowledge among emergency physicians in nonendemic Western countries in the diagnosis and management of commonly encountered tropical diseases. The search was conducted using the following databases: Ovid MEDLINE In-Process \& Other Non-Indexed Citations, Ovid MEDLINE (1948 to August 2011), and EMBASE (1980 to August 2011). The following search terms were used as subject headings or key terms: emergency medicine, hospital emergency service, or emergency medical services; 
tropical or travel; and diarrhea, enterotoxigenic Escherichia coli, E. coli infections, travellers' diarrhea, dengue, dengue virus, typhoid fever, Salmonella typhi, malaria, Plasmodium, tuberculosis, Mycobacterium, or communicable diseases.

Titles and abstracts were initially reviewed by a single reviewer (S.M.) and retained for full-article review if they were found to assess either the diagnosis or treatment of tropical diseases in nonendemic Western countries, including Canada, western Europe, and the United States. Articles published in English, French, or Spanish were included. Review articles providing general disease management were excluded. Case reports were considered if there was a paucity of literature on one of the included disease entities. The list of relevant articles was reviewed independently by a second reviewer (N.M.) to determine articles to be retrieved for full-text assessment. Differences were resolved through discussion. The findings are summarized below.

\section{Survey administered to Canadian emergency physicians}

A modified Dillman methodology was used to develop the survey tool. ${ }^{48}$ Using the results of the literature review and input from emergency physicians with training and expertise in global health and tropical diseases, the accepted minimum standard in the management of patients with tropical diseases was identified to develop case vignettes for the questionnaire. The survey was pilot tested with 10 emergency physicians from both academic and community hospitals in the Greater Toronto region, and revisions were completed based on feedback. The final survey is provided in the Appendix. Ethics board approval was obtained for survey deployment. The online, anonymous national survey was administered to emergency physicians across Canada using the Canadian Association of Emergency Physicians (CAEP) survey deployment service. As the survey addressed training to date and CME opportunities for fully qualified physicians, medical students and residents were excluded. The survey identified self-reported knowledge gaps and assessed tropical disease knowledge through responses to case-based diagnosis and management questions. The survey was deployed in July and August 2012 using one original survey deployment followed by two reminders. The results are summarized using descriptive statistics.

\section{Evaluation of current CME educational resources}

The final component of the study was to identify upto-date resources currently available to provide education in tropical disease to emergency physicians working in Western countries. A list of resource titles was generated from major Western academic emergency medicine journals (Annals of Emergency Medicine, Canadian Fournal of Emergency Medicine, Academic Emergency Medicine, and Fournal Watch Emergency Medicine) from September 2010 to September 2011, Medscape CME articles from April 2011 to September 2011, and topics from two major emergency medicine conferences commonly attended by Canadian emergency physicians (CAEP and American College of Emergency Physicians [ACEP]) for the years 2010 and 2011. Two independent reviewers (Y.K., P.C.) assessed the relevance of the listed resources identifying resources related to global health and narrowed to resources geared toward tropical diseases. Differences were resolved by consensus. The resources available for education in this area are summarized descriptively.

\section{RESULTS}

\section{Literature review}

A total of 635 and 882 articles were retrieved from MEDLINE and EMBASE, respectively, with 1,270 reviewed after removal of 247 duplicates. Forty-seven articles were included in the final literature review. The articles included retrospective chart reviews (66\%), case series or reports $(12.8 \%)$, prospective observational studies $(10.6 \%)$, survey or questionnaire studies $(4.3 \%)$, literature reviews $(4.3 \%)$, and database studies $(2.1 \%)$. Only four $(8.5 \%)$ of the studies were Canadian, and only five $(10.6 \%)$ had an emergency medicine focus. The majority of the articles discussed malaria, with $28.0 \%$ addressing the other tropical diseases searched.

A number of studies suggested that delays in diagnosis $^{2,8-29}$ and misdiagnosis ${ }^{3,9-11,19,20,30-33}$ of tropical diseases, especially malaria, are common in nonendemic countries. The literature demonstrated major gaps in the diagnosis and management of tropical diseases., ${ }^{2,3}$ Nonspecific symptoms, ${ }^{3,9,14,19,33-37}$ a lack of awareness of the diseases in nonendemic regions, ${ }^{15-19,35,38}$ and the failure of physicians to elicit a travel history ${ }^{2-4,8,11,15,17,40,41}$ were reported to lead to both delays in diagnosis and misdiagnoses. Incorrect 
treatment and absence of necessary monitoring led to inappropriate management ${ }^{3,22,35,42-47,49}$

Of the five studies with an emergency medicine focus, three studies showed missed or delayed diagnosis of malaria by emergency physicians in 38.0 to $47.0 \%$ of cases, with hepatitis, gastroenteritis, and viral illnesses accounting for the most common misdiagnoses., ${ }^{3,19,34}$ One study reported a typhoid misdiagnosis rate of $85.7 \% .{ }^{33}$ A United Kingdom-based questionnaire study reported correct diagnosis of imported tropical disease rates by emergency physicians of $22 \% .{ }^{40}$ All four Canadian studies addressed malaria management, and none reported findings on other diseases. ${ }^{8,12,15,40}$

\section{Survey}

\section{Participants' baseline characteristics}

In total, 1,128 surveys were distributed to emergency physicians across Canada through the CAEP survey deployment service. Of the 1,128 surveys distributed, 315 individuals responded, 19 of whom were current medical trainees and excluded, and 296 participant responses were included in the study, for a response proportion of $27.0 \%$.

The baseline characteristics of survey respondents are summarized in Table 1 . The majority of respondents had more than 1 year of experience as an emergency physician (90.3\%), and $48.9 \%$ had been practicing emergency medicine for more than 11 years. In terms of training, $46.6 \%$ of survey participants were $\mathrm{CCFP}(\mathrm{EM})$-trained

\begin{tabular}{|lcr|}
\hline \multicolumn{3}{|c|}{ Table 1. Baseline characteristics of survey respondents } \\
\hline Baseline characteristic & Answer options & $\%$ \\
\hline Years of practice as an & $<1$ & 9.5 \\
emergency physician & $1-5$ & 20.7 \\
& $6-10$ & 20.7 \\
& $11-20$ & 24.8 \\
Emergency medicine & $>20$ & 24.1 \\
training & Family physician & 16.9 \\
& CCFP(EM) & 46.6 \\
& FRCP(EM) & 31.1 \\
Tropical medicine training & Other & 5.4 \\
& No training & 52.4 \\
Tropical medical training & Some training & 45.9 \\
obtained in/by* & Extensive training & 1.7 \\
& Medical school & 46.6 \\
& Residency & 26.4 \\
\hline *Percentages do not add to 100\%. & Self-directed learning \\
\hline
\end{tabular}

physicians, 31.1\% were FRCP(EM)-trained physicians, and $16.9 \%$ were family physicians. A similar proportion of respondents reported "no" training or "some" training in tropical diseases $(52.4 \%$ and $45.9 \%$, respectively), and only $1.7 \%$ of respondents reported "extensive" training. The majority of training was reportedly obtained during medical school (46.6\%), during residency $(26.4 \%)$, and through self-directed learning (14.2\%).

\section{Needs assessment}

The majority of participants $(69.9 \%)$ rated their comfort level in managing patients with tropical diseases as "low," whereas only $2.4 \%$ self-reported a "high" comfort level. In terms of history taking, 56.8\% of emergency physicians reported always asking their patients who present with a fever about recent travel, whereas $41.2 \%$ asked this question "sometimes." Approximately $11.1 \%$ of participants had been involved in or had heard of a misdiagnosed or mismanaged tropical disease case in the past year. Of these, $44.1 \%$ involved malaria management, with the cases involving misdiagnosis due to untimely screening tests or incorrectly arriving at an alternative diagnosis. Other identified diseases were dengue (11.8\%), typhoid (8.8\%), and tuberculosis (5.9\%). Less common diseases were reported in $20.6 \%$ of cases: schistosomiasis, measles, dysentery, leishmaniasis, and neurocysticercosis. The perceived need for further training was high, with $76.7 \%$ of participants asking for more CME activities centred on tropical disease training. In terms of CME activities that participants would use, most participants requested workshops at conferences (71.6\%), with fewer choosing case studies (64.7\%) and podcasts $(40.2 \%)$ as the preferred mode of training.

\section{Case vignette responses}

Case vignettes were included as part of the survey to assess knowledge in terms of the diagnosis and management of tropical diseases. A total of 274 respondents $(92.5 \%)$ completed this section of the survey. Complete results are presented in Table 2. Correct answers to the case vignettes ranged from 30.7 to $58.4 \%$ (mean $45.5 \%$ ). Those unsure of the answers ranged from 7.7 to $47.8 \%$ (mean $29.3 \%$ ).

\section{CME resources evaluation results}

CME titles $(2,038)$ were extracted and independently reviewed by two reviewers, with resource titles retained 
Table 2. Case vignette results

\begin{tabular}{|c|c|c|}
\hline Question & Answer options & $\%$ \\
\hline \multirow{5}{*}{$\begin{array}{l}\text { Case 1: A young man returns from a brief trip to sub-Saharan } \\
\text { Africa's Zambezi River complaining of malaise and occasional } \\
\text { diarrhea of } 2 \text { weeks' duration. Screening laboratory work shows } \\
\text { mild anemia, eosinophilia, and } 2+\text { red blood cells } \\
\text { on dipstick. What is the most likely diagnosis? }\end{array}$} & Malaria & 5.5 \\
\hline & Schistosomiasis & 52.2 \\
\hline & Hookworm & 6.6 \\
\hline & Onchocerciasis & 4.0 \\
\hline & I am not sure & 31.8 \\
\hline \multirow{3}{*}{$\begin{array}{l}\text { Case 2: A refugee is sent to your ED from the nursing home } \\
\text { where he volunteers because in a routine medical screening, he } \\
\text { was found to have a positive tuberculin skin test (which } \\
\text { you confirm on visual inspection). He has no cough, and } \\
\text { his x-ray is normal. Is it safe to discharge him and allow } \\
\text { him to resume his duties? }\end{array}$} & Yes & 58.4 \\
\hline & No & 21.2 \\
\hline & I am not sure & 20.4 \\
\hline \multirow{5}{*}{$\begin{array}{l}\text { Case 3: A 68-year-old male who immigrated to Canada } 2 \\
\text { years ago from a malaria-endemic country and has recently } \\
\text { returned from a 1-month visit back home presents to } \\
\text { hospital feeling generally unwell with intermittent fever } \\
\text { of } 5 \text { days' duration. He is brought in by his family, who } \\
\text { report that he has been intermittently confused on the } \\
\text { day of presentation. At present, he is alert, oriented, and } \\
\text { behaving appropriately, looks well, his vital signs are stable } \\
\text { and within the normal range. Which of the following } \\
\text { statements is true? }\end{array}$} & $\begin{array}{l}\text { The cause of the patient's fever and confusion cannot be } \\
\text { malaria as those living in endemic areas develop immunity to } \\
\text { malaria }\end{array}$ & 0.7 \\
\hline & $\begin{array}{l}\text { A thin and thick blood smear should be sent. If negative, } \\
\text { malaria is ruled out. }\end{array}$ & 28.8 \\
\hline & $\begin{array}{l}\text { The patient should be put on oral antimalarial medication and } \\
\text { followed up at an infectious disease clinic }\end{array}$ & 14.6 \\
\hline & The patient has severe malaria and requires admission & 48.2 \\
\hline & I am not sure & 7.7 \\
\hline \multirow{5}{*}{$\begin{array}{l}\text { Case 4: You have an HIV-positive patient from eastern Africa } \\
\text { who comes to your emergency department with a } \\
\text { decreased level of consciousness. He has recently } \\
\text { obtained refugee status in Canada. He is not on } \\
\text { antiretroviral medications, and his last CD4 count was } 53 \text { cell/ } \mu \mathrm{L} \text {. } \\
\text { His noncontrast CT scan is normal. You perform an LP. } \\
\text { Which of the following are you most likely to find when } \\
\text { testing his CSF? }\end{array}$} & Positive CSF Indian ink stain & 30.7 \\
\hline & Positive Salmonella typhi culture & 1.1 \\
\hline & Positive PCR for dengue & 1.1 \\
\hline & Positive antibody assay for toxoplasmosis & 28.5 \\
\hline & I am not sure & 38.7 \\
\hline \multirow{5}{*}{$\begin{array}{l}\text { Case 5: A patient presents to the ED with fever, constipation, } \\
\text { and malaise. She returned from India } 3 \text { weeks ago after } \\
\text { working in an urban area. She lived there for } 1 \text { year. As } \\
\text { far as she knows, before she left for India, she updated } \\
\text { all the recommended immunizations for travel to India, } \\
\text { including typhoid vaccine. Is it possible for this patient to } \\
\text { have typhoid fever? }\end{array}$} & No, as typhoid immunization provides protection for 2 years & 4.0 \\
\hline & Yes, as typhoid immunization provides only $50 \%$ protection & 38.0 \\
\hline & No, as typhoid fever is not an issue in urban areas & 0.7 \\
\hline & Yes, as typhoid vaccine provides protection only for 6 months & 9.5 \\
\hline & I am not sure & 47.8 \\
\hline
\end{tabular}

if they related to global health. Disagreement on 21 items was resolved through discussion and consensus. Forty-two of the extracted items were found to be educational resources in the field of global health available to emergency physicians. Six conference presentations were identified as educational resources with a single focus on tropical diseases. No journal articles with a focus on tropical diseases were identified.

\section{DISCUSSION}

This multifaceted needs assessment is the first to describe and quantify the status of existing knowledge gaps and the need for dedicated tropical disease CME among Canadian emergency physicians. The majority of survey respondents were experienced emergency physicians, yet most had minimal or no specific training in the management of tropical diseases that commonly present to the ED. Canadian emergency physicians reported an unacceptably low level of comfort when faced with patients presenting with tropical diseases in the ED. Objective knowledge assessment in this study demonstrated that Canadian emergency physicians incorrectly diagnosed or managed clinical cases of tropical diseases $40.0 \%$ of the time. In comparison, a United Kingdom-based questionnaire study using five clinical cases showed incorrect diagnosis of imported tropical disease rates by emergency physicians of $78 \% .{ }^{40}$ 
This national educational needs assessment study demonstrates a strong perceived need for dedicated $\mathrm{CME}$ materials focused on tropical disease training among respondents. Canadian emergency physicians indicated that they would like to receive general reviews and approaches to specific tropical diseases, particularly in the form of workshops, case studies, and podcasts. Our search of the currently published emergency medicine literature indicates that minimal resources are available in this domain. To fill this unmet educational need in the face of an increasing incidence of tropical diseases presenting to Canadian EDs, it is important that Canadian emergency medicine organizations, journals, and academic institutions focus their efforts on generating dedicated educational resources geared specifically toward Canadian emergency physicians. In the meanwhile, all emergency physicians should make efforts to obtain a detailed travel history in all patients with fever and consider malaria, typhoid, dengue, and tuberculosis as part of their differential diagnosis. The Centers for Disease Prevention and Control (CDC) Yellow Book provides an overview of imported tropical diseases based on travel site, ${ }^{50}$ and for the more common diseases, such as malaria and dengue, the CDC maps can be used as a quick reference..$^{51,52}$

There are a number of limitations to our study. First, although a structured literature review was conducted, only two databases were included. No attempt was made to capture the grey literature, and methodological quality was not reported. The CAEP survey deployment tool targets members only, and non-CAEP member emergency physicians would not have been able to participate. Our survey response proportion was low, which may have resulted in sampling bias. There may be a few explanations for the low response rate: the survey was conducted in the summer, which may have been influenced by vacation absence. Although we sent out three survey reminders by email, no regular mail surveys were distributed and incentives were provided.

\section{CONCLUSION}

This multifaceted needs assessment was the first to describe and quantify that most Canadian emergency physicians have had minimal training in tropical diseases, perceived a low comfort level in managing such cases, and identified a high need for CME opportunities. This identified gap warrants further research and new efforts to improve CME opportunities for Canadian emergency physicians in this domain. Several specific educational resources were identified.

Competing interests: None declared. The study was supported by a Continuing Education Research and Development grant awarded by the Office of Continuing Education and Professional Development at the Faculty of Medicine, University of Toronto.

\section{REFERENCES}

1. Knobler S, Mahmoud A, Lemon S, et al. The impact of globalization on infectious disease emergency and control: exploring the consequences and opportunities. Washington (DC): National Academies Press; 2006. Available at: http://www.ncbi.nlm. nih.gov/books/NBK56589/ (accessed April 2011).

2. Ladhani S, Aibara R, Riordan FA, Shingadia D. Imported malaria in children: a review of clinical studies. Lancet 2007; 7:349-57.

3. Kyriacou DN, Spira AM, Talan DA, Mabey DC. Emergency department presentation and misdiagnosis of imported falciparum malaria. Ann Emerg Med 1996;27:6969, doi:10.1016/S0196-0644(96)70186-5.

4. Suaya JA, Shepard DS, Beatty ME. Dengue: burden of disease and cost of illness. Geneva: World Health Organization on Behalf of the Special Programme for Research and Training in Tropical Disease; 2006. Available at: http://www.who.int/ tdr/publications/documents/swg_dengue_2.pdf (accessed September 2011).

5. Candel FJ, Alramadan M, Bonilla I, et al. Malaria, a growing disease. Analysis of the 15-year period 1997-2001 in a Madrid hospital. An Med Intern 2004;21:49-50.

6. Fuentes Soriano MI, Ruiz-Giardin JM, Sanz J. Paludism: emergent diagnosis. Descriptive study of 25 cases. Rev Clin Esp 2006;206:491-4, doi:10.1016/S0014-2565(06)72874-0.

7. Alvarez Fernandez B, Garcia Esteban C, Soto Insuga V, et al. Malaria in the south of Madrid: a clinical and epidemiological review. An Pediatr 2009;71:196-200, doi:10.1016/j.anpedi. 2009.05.016.

8. Svenson JE, MacLean JD, Gyorkos TW, Keystone J. Imported malaria. Clinical presentation and examination of symptomatic travelers. Arch Intern Med 1995;155:861-8, doi:10.1001/archinte.1995.00430080109013.

9. Emanuel B, Aronson N, Shulman S. Malaria in children in Chicago. Pediatrics 1993;92:83-5.

10. Viani RM, Bromberg K. Pediatric imported malaria in New York: delayed diagnosis. Clin Pediatr 1999;38:333-7, doi:10. 1177/000992289903800603.

11. Dorsey G, Gandhi M, Oyugi JH, Rosenthal PJ. Difficulties in the prevention, diagnosis, and treatment of imported malaria. Arch Intern Med 2000;160:2505-10, doi:10.1001/ archinte.160.16.2505

12. Kain KC, MacPherson DW, Kelton T, et al. Malaria deaths in visitors to Canada and in Canadian travellers: a case series. CMA7 2001;164:654-9. 
13. Williams JP, Chitre M, Sharland M. Increasing Plasmodium falciparum malaria in southwest London: a 25 year observational study. Arch Dis Child 2002;86:428-30, doi:10.1136/ adc.86.6.428.

14. Hesselink DA, Yoo SM, Verhoeven GT, et al. A high prevalence of culture-positive extrapulmonary tuberculosis in a large Dutch teaching hospital. Neth 7 Med 2003;61: 65-70.

15. Kambili C, Murray HW, Golightly LM. Malaria: 30 years of experience at a New York City teaching hospital. Am 7 Trop Med Hyg 2004;70:408-11.

16. Miller KK, Banerji A. Epidemiology of malaria presenting at British Columbia's Children's Hospital, 1984-2001: lessons for prevention. Can 7 Public Health 2004;95:245-8.

17. Vicas AE, Albrecht H, Lennox JL, del Rio C. Imported malaria at an inner-city hospital in the United States. Am 7 Med Sci 2005;329:6-12, doi:10.1097/00000441-200501000$\underline{00002}$

18. Ben-Ami R, Siegman-Igra Y, Anis E, et al. Malaria in travelers returning from short organized tours to holiday resorts in Mombassa, Kenya. Isr Med Assoc 7 2005;7:364-7.

19. Chalumeau M, Holvoet L, Cheron G, et al. Delay in diagnosis of imported Plasmodium falciparum malaria in children. Eur f Clin Microbiol Infect Dis 2006;25:186-9, doi:10.1007/s10096-006-0105-3.

20. Christen D, Steffen R, Schlagenhauf P. Deaths caused by malaria in Switzerland 1988-2002. Am 7 Trop Med Hyg 2006; 75:1188-94.

21. Thierfelder C, Schill C, Hatz C, Nuesch R. Trends in imported malaria to Basel, Switzerland. 7 Travel Med 2008; 15:432-6, doi:10.1111/j.1708-8305.2008.00251.x.

22. Kain KC, Harrington MA, Tennyson S, Keystone JS. Imported malaria: prospective analysis of problems in diagnosis and management. Clin Infect Dis 1998;27:142-9, doi: $10.1086 / 514616$.

23. Kean BH, Reilly PC Jr. Malaria - the mime. Recent lessons from a group of civilian travelers. Am 7 Med 1976;61:159-64, doi:10.1016/0002-9343(76)90164-9.

24. Kortepeter M, Brown JD. A review of 79 patients with malaria seen at a military hospital in Hawaii from 1979 to 1995. Mil Med 1998;163:84-9.

25. Hoshino Y, Masuda G, Negishi M, et al. Clinical and bacteriological profiles of patients with typhoid fever treated during 1975-1998 in the Tokyo Metropolitan Komagome Hospital. Microbiol Immunol 2000;44:577-83.

26. Rugina S, Dumitru IM, Cernat RC. Imported cutaneous and visceral leishmaniasis cases in Constanta, Romania. Trop Med Int Health 2009;14:187-8.

27. Charra B, Sodqi M, Sandali O, et al. Imported severe malaria in adults: a retrospective study of ten cases admitted to intensive care units in Casablanca. Med Mal Infect 2007;37: 162-5, doi:10.1016/j.medmal.2006.09.006.

28. Pistone T, Diallo A, Receveur MC, et al. Le paludisme d'importation au CHU de Bordeaux de 2000 à 2007: épidémiologie, prise en charge et comparaison avec les données nationals. Bull Soc Pathol Exot 2009;103:104-10, doi:10.1007/s13149-010-0045-4.

29. Laferl H, Szell M, Bischof E, Wenisch C. Imported dengue fever in Austria 1990-2005. Travel Med Infect Dis 2006;4:31923, doi:10.1016/j.tmaid.2005.10.001.
30. Winters RA, Murray HW. Malaria-the mime revisited: fifteen more years of experience at a New York City teaching hospital. Am 7 Med 1992;93:243-6, doi:10.1016/00029343(92)90228-4.

31. Ohnishi K, Murata M. Malaria-eight years of experience in a Tokyo metropolitan hospital. Int Med 1996;35:111-4, doi:10.2169/internalmedicine.35.111.

32. Klein JL, Millman G. Prospective, hospital based study of fever in children in the United Kingdom who had recently spent time in the tropics. $B r$ Med 7 1998;316:1425-6, doi:10.1136/bmj.316.7142.1425.

33. Hoffner RJ, Slaven E, Perez J, et al. Emergency department presentations of typhoid fever. 7 Emerg Med 2000;19:317-21, doi:10.1016/S0736-4679(00)00260-2.

34. Kockaerts Y, Vanhees S, Knockaert DC, et al. Imported malaria in the 1990s: a review of 101 patients. Eur 7 Emerg Med 2001;8:287-90, doi:10.1097/00063110-200112000-00007.

35. Chung HC, Wang JT, Sun HY, et al. Clinical experience of 17 cases of imported malaria at a Taiwan university hospital, 1999-2005. 7 Microbiol Immunol Infect 2007;40:209-15.

36. Moore DA, McCroddan J, Dekumyoy P, Chiodini PL. Gnathostomiasis: an emerging imported disease. Emerg Infect Dis 2003;9:647-50, doi:10.3201/eid0906.020625.

37. Minodier P, Lanza-Silhol F, Piarroux R, et al. Imported malaria in children in Marseilles. Arch Pediatr Adolesc Med 1999;6:935-43.

38. Yu JR, Sohn W. A case of human cyclosporiasis causing traveler's diarrhea after visiting Indonesia. $\mathcal{F}$ Korean Med Sci 2003;18:738-41.

39. Flaherty G, Scott A, O'Brien T. Recognition of tropical illness in the returned traveller by healthcare professionals working in an Irish university teaching hospital. Trop Med Int Health 2009;14 Suppl 2:79.

40. Smith SM. Imported disease in emergency departments: an undiscovered country? 7 Travel Med 2006;13:73-7, doi:10.1111/j.1708-8305.2006.00019.x.

41. Matteelli A, Volonterio A, Gulletta M, et al. Malaria in illegal Chinese immigrants, Italy. Emerg Infect Dis 2001;7: 1055-8, doi:10.3201/eid0706.010628.

42. Robinson $\mathrm{P}$, Jenney $\mathrm{AW}$, Tachado $M$, et al. Imported malaria treated in Melbourne, Australia: epidemiology and clinical features in 246 patients 7 Travel Med 2001;8:76-81, doi: $10.2310 / 7060.2001 .24309$.

43. Singh K, Wester WC, Trenholme GM. Problems in the therapy for imported malaria in the United States. Arch Intern Med 2003;163:2027-30, doi:10.1001/archinte.163. 17.2027

44. Newman RD, Parise ME, Barber AM, Steketee RW. Malaria-related deaths among U.S. travelers, 1963-2001. Ann Intern Med 2004;141:547-55, doi:10.7326/0003-4819141-7-200410050-00012.

45. Leahy TR, Malikiwi A, Cafferkey M, Butler KM. Imported childhood malaria: the Dublin experience, 1999-2006. Ir 7 Med Sci 2009;178:329-32, doi:10.1007/ s11845-009-0343-3.

46. Goldfarb DM, Gaboury I, Dayneka N, Saux NL. Protocol for management of imported pediatric malaria decreases time to medication administration. Pediatr Infect Dis 7 2009; 28:810-3, doi:10.1097/INF.0b013e3181a3d12f. 
47. Elmansouf L, Dubos F, Dauriac A, et al. Evaluation of imported pediatric malaria management in northern France. Med Mal Infect 2011;41:145-51, doi:10.1016/j.medmal.2010. 11.010 .

48. Dillman DA. Mail and Internet surveys: the Tailored Design Method. 2nd ed. New York: Wiley; 2007.

49. Debelleix MP, Receveur MC, Pistone T, et al. One hundred and fifteen cases of imported falciparum malaria admitted at the Bordeaux teaching hospital emergency unit. Med Mal Infect 2009;40:88-93, doi:10.1016/j.medmal. 2009.08.008.

50. Centers for Disease Control and Prevention. Select Destinations. In: Yellow Book. Available at: http://wwwnc. cdc.gov/travel/yellowbook/2012/table-of-contents.htm (accessed May 2013).

51. Centers for Disease Control and Prevention, Malaria map application. Available at: http://cdc-malaria.ncsa.uiuc.edu/ (accessed May 2013).

52. Centers for Disease Control and Prevention, Dengue map. Available at: http://www.healthmap.org/dengue/ (accessed May 2013).

\section{APPENDIX: SURVEY QUESTIONS}

How many years have you practiced as an emergency physician?
a) $<1$ year
b) 1-5 years
c) 6-10 years
d) 11-20 years
e) $>20$ years

What is your training?
a) Family physician
b) $\mathrm{CCFP}(\mathrm{EM})$
c) $\mathrm{FRCP}(\mathrm{EM})$
d) Other (please specify)

How much training do you have in tropical diseases?
a) No training
b) Some training
c) Extensive training

Where did you obtain your tropical medical training? (tick all that apply)
a) Medical school
b) Part of residency training
c) Sought out training on my own (please describe in text box below)

Please describe your extra training here. (text box follows)
Please rate your comfort level in managing patients with tropical diseases.
a) Low
b) Medium
c) High

How often do you ask your patients with fever if they have recently travelled?
a) Never
b) Sometimes
c) Always

Do you know of a tropical disease case that you or a colleague misdiagnosed or mismanaged in the last year?
a) Yes
b) $\mathrm{No}$

If yes, please provide a brief description of the case and problem(s) encountered.

In your opinion, do you perceive a need for more continuing medical education (CME) activities focused on tropical diseases?
a) Yes
b) No

If yes, please briefly describe what you think is needed and why.

Please choose which of the following CME tools you would use. (tick all that apply)

a) Case studies (e.g., similar to Medscape CME case studies)

b) Workshops at conferences

c) Podcasts

d) Other (please specify)

Case-Based Vignettes

1. A young man returns from a brief trip to subSaharan Africa's Zambezi River complaining of malaise and occasional diarrhea of 2 weeks' duration. Screening laboratory work shows mild anemia, eosinophilia, and $2+$ red blood cells on dipstick. What is the most likely diagnosis?
a. Malaria
b. Schistosomiasis 

c. Hookworm
d. Onchocerciasis
e. I am not sure

2. A refugee is sent to your emergency department from the nursing home where he volunteers because in a routine medical screening, he was found to have a positive tuberculin skin test (which you confirm on visual inspection). He has no cough, and his x-ray is normal. Is it safe to discharge him and allow him to resume his duties?
a. Yes
b. No
c. I am not sure

3. A 68-year-old male who immigrated to Canada 2 years ago from a malaria-endemic country and has recently returned from a 1-month visit back home presents to hospital feeling generally unwell with intermittent fever of 5 days' duration. He is brought in by his family, who report that he has been intermittently confused on the day of presentation. At present he is alert, oriented and behaving appropriately, looks well, his vital signs are stable and within the normal range. Which of the following statements is true?

a. The cause of the patient's fever and confusion cannot be malaria as those living in endemic areas develop immunity to malaria

b. A thin and thick blood smear should be sent. If negative, malaria is ruled out.

c. The patient should be put on oral antimalarial medication and followed up at an infectious disease clinic

d. The patient has severe malaria and requires admission
e. I am not sure

4. You have a human immunodeficiency virus (HIV)positive patient from eastern Africa who comes to your emergency department with a decreased level of consciousness. He has recently obtained refugee status in Canada. He is not on antiretroviral medications, and his last CD4 count was 53 cells/ $\mu \mathrm{L}$. His noncontrast computed tomographic scan is normal. You perform a lumbar puncture. Which of the following are you most likely to find when testing his cerebrospinal fluid (CSF)?
a. Positive CSF Indian ink stain
b. Positive Salmonella typhi culture
c. Positive polymerase chain reaction for dengue
d. Positive antibody assay for toxoplasmosis
e. I am not sure

5. A patient presents to the emergency department with fever, constipation, and malaise. She returned from India 3 weeks ago after working in an urban area. She lived there for 1 year. As far as she knows, before she left for India, she updated all the recommended immunizations for travel to India, including typhoid vaccine. Is it possible for this patient to have typhoid fever?

a. No, as typhoid immunization provides protection for 2 years

b. Yes, as typhoid immunization provides only $50 \%$ protection

c. No, as typhoid fever is not an issue in urban areas

d. Yes, as typhoid vaccine provides protection only for 6 months

e. I am not sure 